\title{
UNA OJEADA AL PANORAMA ARQUITECTONICO ACTUAL
}

\section{(A BRIEF OVERVIEW OF CONTEMPORARY ARCHITECTURE)}

\author{
M. Fisac, Dr. Arquitecto
}

Fecha de recepción: $25-\mathrm{XI}-88$

RESUMEN

La gran personalidad y espíritu polémico del autor de este artículo se manifiestan en el enfoque y en el planteamiento que hace de la arquitectura, como protagonista cultural y como rectora de las restantes artes plásticas.

Analiza un proceso creador, sus resultados formales y su entronque con la sociedad actual, y teme que éste se halle al final decepcionante de una etapa utópica de la Humanidad.

Por último, plantea un interesante interrogante y esboza posibles soluciones.

\section{SUMMARY}

The great personality and spirit of the polemic of its author are apparent in this article in his approach to architecture and his interpretation of it as a protagonist of culture and governing factor over the other plastic arts.

He analyses a creative process, its formal results and how it relates to today's society, expressing the fear that the said process comes at the disappointing finale of a Utopian stage in the history of Humanity.

Finally, he poses an interesting question, and outlines possible solutions.
Cuando se lleva, casi medio siglo, contemplando apa. sionadamente los acontecimientos arquitectónicos cer. canos y lejanos, se está en condiciones de valorar en su verdadera dimensión la andadura de una Revista, que como INFORMES DE LA CONSTRUCCION, mes a mes y durante cuarenta años, ha testificado, con seriedad profesional y con una impecable presentación, lo que ha ido apareciendo en el panorama arquitectónico español y extranjero.

Como homenaje a ese buen hacer de esta Publicación del INSTITUTO EDUARDO TORROJA de la Construcción y del Cemento, con la que siempre he mantenido excelentes relaciones y tantas veces me ha honrado con la publicación de muchas de mis obras, querría hacer algunos comentarios sobre el momento actual de la arquitectura.

Es evidente que el planteamiento que yo hago de la arquitectura: su proceso creador, sus resultados forma- les y hasta su entroncamiento con la sociedad de nuestro tiempo, es radicalmente distinto, si no opuesto, a lo que hacen y dicen los arquitectos más conspicuos del momento actual.

De otra parte, es evidente también el protagonismo cultural que la arquitectura actual está teniendo y que le sitúa como rectora y orientadora de las otras artes plásticas; situación privilegiada que desde hacia mucho tiempo no disfrutaba.

He procurado analizar estos fenómenos con la máxima objetividad y estoy dispuesto a rectificar mis puntos de vista si hubiera razones que lo justificasen; pero no las encuentro.

¿Cómo se puede explicar esta situación tan contradictoria en la que, de una parte, existe una decadente descomposición, frivolidad, etc., y de otra, unos resultados tan generalizadamente aceptados y hasta solicitados 


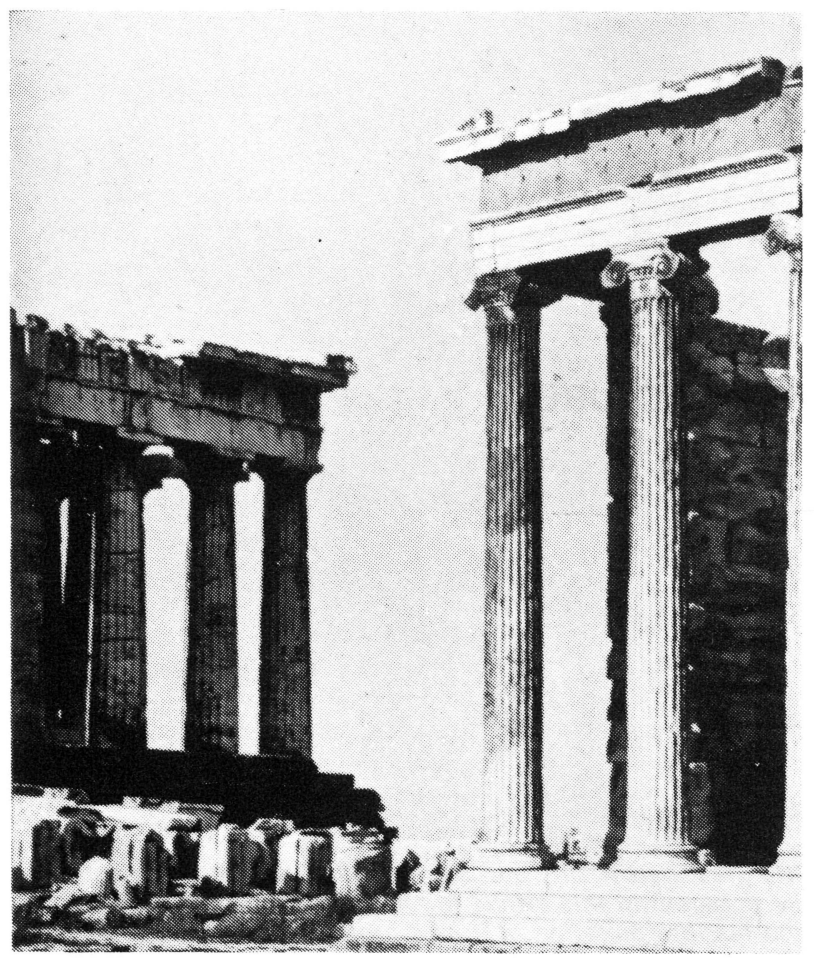

por los dirigentes de la sociedad actual: intelectuales, políticos, hombres de negocios, etcétera?

Creo que esta aparente contradicción es perfectamente explicable, aunque más que un artículo, exigiría un libro de muchas páginas y escrito por alguien que dispusiera de una documentación y unos conocimientos filosóficos, sociológicos e históricos de los que yo carezco.

Para hacer este análisis no cuento más que con una cierta intuición, seguida del conocimiento de algunos datos que la experiencia de muchos años me ha ido suministrando y, sobre todo, una enorme curiosidad por desentrañar la esencia de ese fenómeno genuinamente humano que es la arquitectura y que tanto me ha ocupado y preocupado a lo largo de mi vida.

De forma telegráfica, se podría decir que el hombre necesita la arquitectura ante una naturaleza que le es hostil. Su evolución (la del nombre) le pone en posesión de unas facultades, no sólo cognoscitivas y volitivas, sino también de unos sentimientos conscientes e inconscientes que necesita expresar y es entonces cuando la construcción de espacios acotados transciende al arte de la arquitectura. Y la arquitectura de esta forma unívoca, pasa a ser, en cada momento de la Historia, la expresión de los anhelos del individuo, así como la ciudad lo es de la colectividad.
En la secuencia del desarrollo de un estilo, arquitectónico en este caso, considera Hegel que existe un período, que llama simbólico, en que la idea aún inmadura necesita recurrir a signos comparativos para expresar la forma. Lo clásico vendría a ser el equilibrio entre idea y forma y un tercer estadio de evolución sería aquel que denomina romántico, que el desequilibrio entre idea y forma se vuelca a favor de esta última; que se trivializa, se desmadra, pierde densidad y termina en un puro disparate decadente.

La historia del Arte está llena de ejemplos en los que se puede claramente apreciar que eso que podríamos llamar ideal, ilusión, siempre ha desarrollado unas consecuencias filosóficas que se han materializado en una expresión plástica y también literaria; poética principalmente. $Y$ todos los síntomas nos inclinan a suponer que hoy estamos en el final decepcionante de una de esas etapas en la que los hombres creían que encontrarian la felicidad.

El desarrollo extraordinario de las ciencias positivas cada vez más rápido y de mayor brillantez, seguido de unas tecnologías aún más impresionantes, nos han enfrentado con un mundo para el que no estábamos preparados y nos han sumido en algo muy parecido a un caos. $Y$, ese caos, hay que reconocer que no puede tener mejor expresión plástica que la que está dando la arquitectura que se hace en este momento.

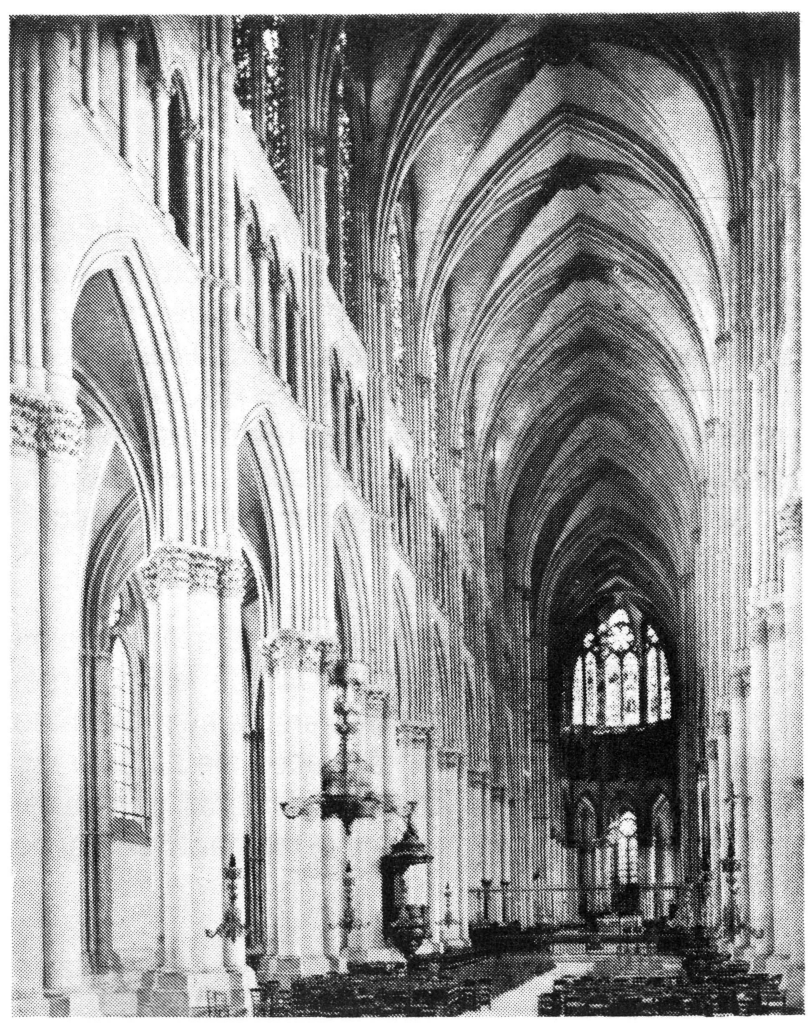

http://informesdelaconstruccion.revistas.csic.es 


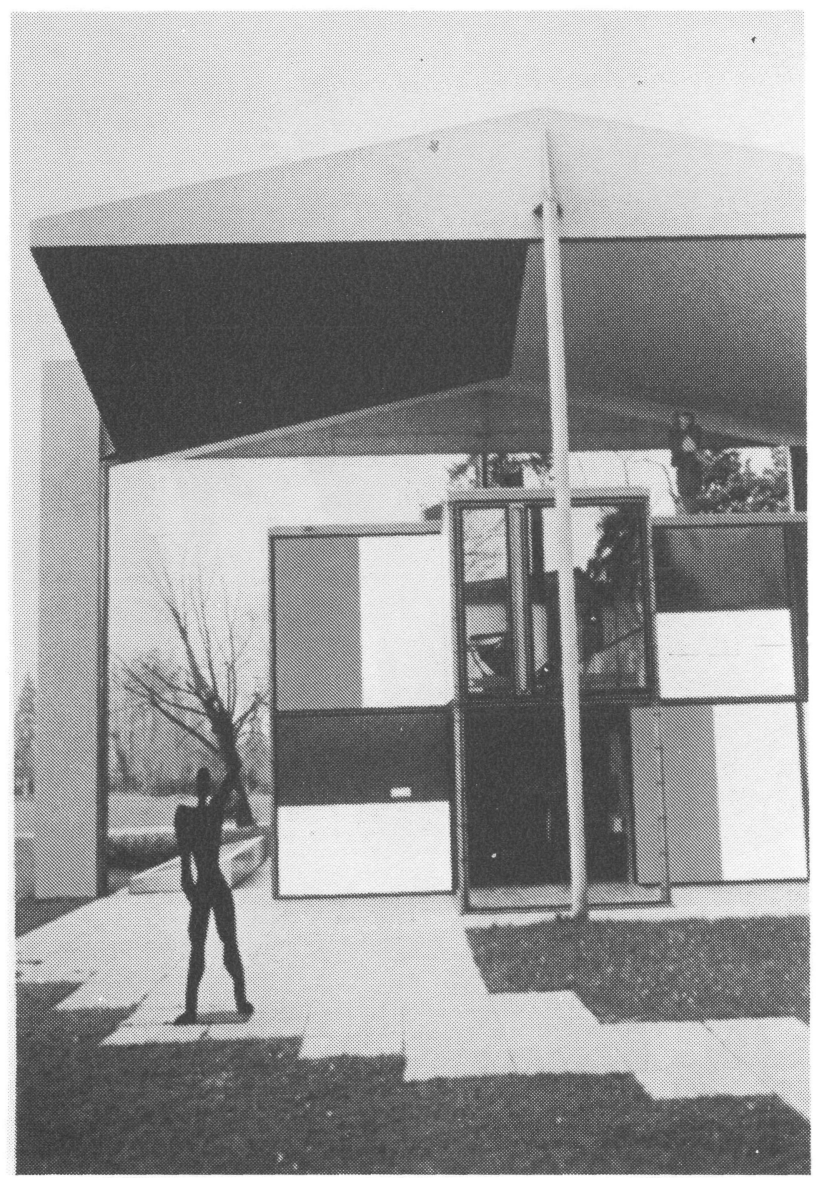

A mayor abundamiento de la calidad del fenómeno arquitectónico que vivimos, se puede apreciar que el programa guía de esta arquitectura la tiene, sin ninguna duda, la del Museo: Precisamente el edificio marginado de la vida real, que recrea nostalgias.

¿Cómo salir de esta situación? En otros casos, las guerras han impuesto un borrón y cuenta nueva, muy oportunos dentro de su salvajismo, pero hoy sabemos que una guerra sería un holocausto total.

De una abundantísima cosecha de ideales políticos y sociales que nos suministró el siglo XIX y que tuvieron su expresión arquitectónica y urbanística en los dos grandes modelos progresista y culturalista que Françoise Choay estudia en "L'urbanisme utopies et réalités", han surgido dos secuencias que rápidamente han ido complicándose y degradándose hasta llegar a resultados insensatos.

Lo más probable, y también lo más deseable, tal vez sería que se fueran formando - de hecho ya han hecho su aparición- pequeños grupos de gentes sensatas, y de buena voluntad que lenta y decididamente vayan preparando un ambiente que propicie el respeto a la vida, a los derechos humanos, a la naturaleza, y el deseo de preparar en la paz interior la creación de una sociedad libre, pacífica y justa; condición previa para una buena arquitectura y un buen urbanismo.

\section{publicación del IETcc / CISC}

\section{ACUEDUCTOS ROMANOS EN ESPAÑA Carlos Fernández Casado} Prof. Dr. Ing. de Caminos, Canales y Puertos

Esta publicación se compone de una serie de articulos, publicados en la Revista "Informes de la Construcción", en los cuales se hace un análisis de los acueductos romanos que existen en España y el balance de las condiciones de conservación en que se encuentra cada uno de ellos, incluyendo referencias históricas y literarias. Se ha ilustrado con la reproducción de la valiosa documentación gráfica que posee el prestigioso autor.

Un volumen encuadernado en couché, a dos colores, de $21 \times 27$ centímetros, compuesto de 238 páginas, numerosos grabados, dibujos, fotos en blanco y negro y figuras de linea.

Precio: España, 1.500 ptas., 21 \$ USA.

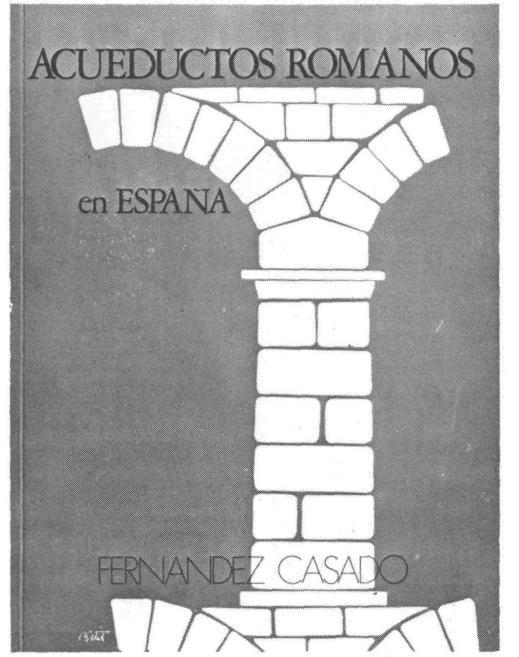

